\title{
Las artes en la educación plena e integral del desarrollo psíquico humano
}

\author{
The arts in the full and integral education of human psychic \\ development
}

\section{As artes na educação plena e integral do desenvolvimento psíquico humano}

\author{
Maria Eliza Mattosinho Bernardes' \\ Universidade de São Paulo, Escola de Artes, Ciências e Humanidades, Professora. \\ https://orcid.org/0000-0003-4958-5647 \\ Guillermo Arias Beatón \\ Universidad de Havana, Faculdade de Psicologia, Professor Titular. \\ https://orcid.org/0000-0002-0333-8264 \\ Laura Marisa Carnielo Calejon ${ }^{3}$ \\ Universidade Estadual do Mato Grosso do Sul, Laboratório de Formação Docente do Centro \\ de Ensino, Pesquisa e Extensão em Educação, Pesquisadora Convidada. \\ https://orcid.org/0000-0002-0333-8264
}

Resumen: En el trabajo se analizan, desde el enfoque histórico cultural, las condiciones y determinantes, la organización y ejecución, de una educación de calidad e integral, que garantice el aprendizaje y el desarrollo psíquico humano pleno. Se insiste en la historia y orígenes, de la concepción total de la formación de las personas, a partir de su educación emocional, intelectual, artística y deportiva desde la Antigua Grecia con la Paideia, que, aunque de naturaleza elitista, se constituyó en los indicios de esta importante educación. Se profundiza en el papel de las artes en su estrecha e indivisible interrelación con los conocimientos científicos en la formación plena e integral del sujeto. Se debaten algunos aspectos de carácter metodológicos, sobre cómo emplear las artes y las ciencias en esta educación. Se parte de que esta labor es de naturaleza social y cultural esencialmente, porque, aunque lo biológico, lo genético y fisiológico participa, son los contenidos y medios de la cultura, los que conforman, en definitiva, la constitución de los procesos psíquicos específicamente humanos, los

Doutora e Mestre em Educação pela Faculdade de Educação da Universidade de São Paulo.

2 Doutor em Ciências Pedagógicas pelo Instituto Central de Ciências Pedagógicas de Cuba; Mestre em Psicodrama e Processos Grupais pela Universidad de La Habana.

3 Doutora em Psicologia Escolar e do Desenvolvimento Humano pelo Instituto de Psicologia da Usp; Mestre em Psicologia da Saúde pela Universidade Metodista de São Paulo. 
sistemas psicológicos más complejos como la conciencia, el pensamiento verbal, la concepción del mundo del sujeto y su personalidad.

Palabras claves: Educación integral. Desarrollo. Aprendizajes. Artes.

Abstract: This work analyzes, from the cultural historical approach perspective, the conditions and determinants, the organization and the implementation of a quality and integral education, which guarantees the learning and the full human psychic development. It insists on history and origins, on the total conception of the formation of people, from their emotional, intellectual, artistic and sports education from Ancient Greece to the Paideia, which, although of an elitist nature, was constituted in them indications of this important education. It deepens the role of the arts and its close and indivisible interrelation with scientific knowledge in the full and integral formation of the subject. Some methodological aspects are debated, about how to use the arts and sciences in this education. It is based on the fact that these works are of a social and cultural nature, mainly because they are biological, genetic and physiological, they participate in and contain culture media, which ultimately make up the constitution of specifically human psychic processes, the most complex psychological systems like awareness, verbal thinking, the design of the world of the subject and their personality.

Keywords: Integral education. Development. Apprenticeships. Arts.

Resumo: No trabalho, são analisadas as condições e determinantes, da organização e execução, de uma educação de qualidade e integral na perspectiva histórico-cultural, que promova a aprendizagem e o pleno desenvolvimento psíquico humano. Insiste na história e nas origens, na concepção total da formação das pessoas, a partir de sua formação emocional, intelectual, artística e esportiva desde a Grécia Antiga com a Paideia, que, embora de natureza elitista, se constituiu nos indícios desta importante educação. Investiga-se o papel das artes em sua inter-relação íntima e indivisível com o conhecimento científico na formação plena e integral do sujeito. Alguns aspectos de caráter metodológicos são discutidos, considerando como usar as artes e ciências nesta educação. Parte-se do fato de que este trabalho é essencialmente de cunho social e cultural, pois embora o biológico, o genético e o fisiológico participem, são os conteúdos e os meios da cultura que acabam por conformar os processos psíquicos especificamente humanos e os sistemas psicológicos mais complexos, como a consciência, pensamento verbal, a concepção de mundo desenvolvida pelo sujeito e sua personalidade. Palavras-chave: educação integral, desenvolvimento, aprendizagem, artes. 


\section{INTRODUCCIÓN}

El Arte [...] no es un producto aislado de una mente activa, sino el resultado de la común aptitud artística en constante ejercicio. No es una manifestación exclusiva: sino una condición esencial. Ha de estar en todo, para que esté en algo. Por la vista van las impresiones artísticas a la mente, que guía luego la mano: ésta devuelve lo que a ella envían. -Las manos producen en analogía con lo que los ojos miran. (MARTí, 1975, p. 134, t. 21).

El objetivo del estudio, aqui presentado, es realizar algunas reflexiones teóricas y metodológicas sobre la educación integral, considerada plena y de calidad, a partir de la orientación de pensadores cubanos del siglo XIX y XX y del enfoque histórico-cultural, que tiene sus raices teórico-metodológica en los presupuestos del materialismo dialéctico e histórico y, de lo mejor del conocimiento pedagógico y psicológico de todos los tiempos.

Este concepto de educación integral es diferente del de educación en tiempo integral. Nosotros en nuestra concepción, concordamos con Gadotti (2009, p. 21) que identifica la educación integral con la que "....] Marx prefería llamarla de educación 'omnilateral.' La educación integral, para Aristóteles, era la educación que hacía florecer todas las potencialidades humanas." A partir del pensamiento de Marx y Aristóteles, reiteramos que nuestro entendimiento de la educación integral es como actividad transformadora de la realidad interna y externa de los seres humanos. Asumimos también que cualquier análisis sobre la temática en cuestión no puede dejar de tener una orientación política explíita, como sentido esencial y claro de lo que representa para nosotros la educación considerada transformadora.

En concordancia con las ideas de José Marti (1975), pensamos que todo análisis de este tipo incluye, necesariamente, los aspectos políticos e ideológicos, no obstante tengamos la intención de negarlo. Asumimos conscientemente que nuestra función social como investigadores de la educación que integran el enfoque histórico-cultural en la América Latina, requiere de una orientación de resistencia y de lucha en busca de procesos educativos humanizados y humanizadores para todas las personas que integran la sociedad. Conforme dijo José Martí, Héroe Nacional y Apóstol de Cuba en el Hardman Hall de Nueva York, en 1892, tres años antes de morir en combate luchando por ideales éticos parecidos a los que nos ocupan, "[...] la política, es el modo de hacer felices a los pueblos, es el deber y el interés primero de quien aspira a ser feliz, y entiende que no lo puede ni merece ser quien no contribuya a la felicidad de los demás." (MARTí, 1975, p. 303).

En lo que nos dice ese pensamiento creemos, y es lo que nos hace luchar en este terreno. No son estéticas, ni bellas, ni racionales, ni justas y por lo tanto verdaderamente humanas, las llamadas politicas que se elaboran y practican hoy en el mundo sobre la vida 
y la educación de los seres humanos, por la felicidad de los pueblos, cuando se habla de educación de calidad y de formación integral, si, los índices de escolares que no aprenden o no aprenden bien, desertan de las escuelas o fracasan escolarmente, alcanzan porcentajes muy elevados que pueden estar entre un $20 \%$ y un $30 \%$.

Comenio (1983) nos orienta cuando afirma, hace más de 300 años, que todos los niños pueden aprender, incluso aquellos que aprenden con mayores dificultades y lentitud, si se les ayuda particularmente, y de acuerdo con sus necesidades y características, también consiguen aprender. Desde el siglo XVI se sabe, por los esfuerzos del Padre Pedro Ponce de León (ARIAS BEATÓN, 2005a), que las personas sordas que no adquieren el lenguaje, si se les enseña por los medios culturales apropiados a sus necesidades y características producidas por el déficit biológico que portan, también pueden aprender como cualquier otra persona e incluso pueden llegar a articular el lenguaje para una comunicación por diferentes vías, la de señas, la dactilóógica e incluso la oral.

Nosotros nos preguntamos, como también se preguntaron, Comenio (1983), Rousseau (1973), Montessori (2003), si estos tipos de escolares, pueden aprender los contenidos y medios de la cultura y desarrollar los procesos intelectuales, afectivos y volitivos como cualquier otra persona, ટ̇cómo es posible que aquellos que se dicen que portan déficit de atención, hiperactividad y dificultades de aprendizaje, no pueden aprender y fracasan en las escuelas de hoy?

De acuerdo con lo que hemos aprendido con lo producido en la historia de la cultura de la humanidad por decenas de pensadores ilustres, se puede afirmar que la educación integral y plena por la que abogamos, es aquella que contiene, los contenidos y medios de la cultura producidos por la sociedad humana durante siglos.

Sabemos lo que hay que hacer para asegurar una educación de calidad que garantice la mediación de los elementos de la cultura históricamente elaborados, como la ciencia, el arte, la filosofia, la politica (HELLER, 2008), en tanto emplee los medios correspondientes para la educación, aprendizaje y desarrollo de las personas, independiente de sus características fisicas y psíquicas individuales como el ciego, sordos-ciegos y con deficiencia mental.

Esta es, entonces, la educación que merecen las nuevas generaciones, que en un tiempo y una historia individual relativamente breve, es aprehendida y apropiada por ellas, garantizando la formación y desarrollo de los procesos afectivos-motivacionales, intelectuales y volitivos necesarios para que las personas posean un pensamiento y una conciencia crítica capaz de explicar sus orígenes y existencia humana, obrar y producir en consecuencia mayores y mejores contenidos y medios para el futuro de la cultura humana.

Ninguna educación que no garantice los mejores aprendizajes en los diferentes tipos de escolares, incluyendo los que presentan algún tipo de déficit biológico y por lo contrario 
engendre y produzca analfabetismo en la lectura, la escritura y el cálculo, generando fracaso escolar o abandono temprano de los estudios, puede y debe ser considerada de calidad, no obstante, los discursos y normas que la declaren como tal.

Las reflexiones presentadas en este texto son el resultado de una colaboración sistemática entre los autores, ${ }^{4}$ que buscan profundizar en el enfoque histórico-cultural y su contribución para lograr una educación plena y de calidad conforme a las indicaciones de la UNESCO (2008, p. 12, grifo do autor) que afirma: "La calidad de la educación, por el carácter del derecho fundamental y universal, tiene que reunir, con base en la perspectiva de la OREALC/ UNESCO Santiago, las siguientes dimensiones: respeto a los derechos, relevancia, pertinencia, equidad, eficiencia y eficacia." No obstante, un análisis objetivo de la cualidad de la educación en los contextos educacionales nos muestra, los grandes desafios que se nos presentan para lograr una educación integral y una educación escolar que sea de calidad.

Por otra parte, consideramos que una educación escolar de calidad e integral ha de contar con una educación temprana y preescolar promotora del desarrollo humano básico e inicial para una labor escolar con éxitos en el proceso de apropiación de los medios culturales esenciales, tales como la lectura, la escritura y el cálculo, los que permitirán continuar el proceso de la educación plena e integral que defendemos.

Hemos llegado a comprender en nuestras labores científicas, académicas y profesionales (ARIAS BEATÓN, 2005b; BERNARDES, 2012; CALEJON, 2012), estudiando los trabajos de la teoría y enfoque histórico cultural y del marxismo, la relación que existe, salvando las condiciones del tiempo y de la historia. Entre estos conocimientos resaltamos el legado de los pensadores cubanos del siglo XIX, que crearon una pedagogía y una educación para un proyecto social revolucionario de nación y de patria, que permitiera formar y desarrollar en las jóvenes generaciones, de finales del siglo XVIII y el XIX, la conciencia necesaria para luchar contra el colonialismo y conseguir ser libres e independientes.

Tenemos la hipótesis de que estudiando los trabajos teórico-prácticos desarrollados por los luchadores por la justicia social y la ética, por lo racional y lo bello de la sociedad humana en América Latina, encontraremos, entre las hojarascas que habrá que analizar críticamente, nuestras mejores y originales formas de pensar humanista y pedagógica (CABALLERO, 2001a, 2001b, 2001c). El pensamiento de los inicios del siglo XX presentada por el autor citado, sostiene aun nuestra lucha por una educación humanizada e integral y por la superación del colonialismo que marca a América Latina. Para la educación cubana, estos pensadores legaron una herencia fundamental.

4 Resaltamos las producciones de Guillermo Arias Beatón y de sus esfuerzos como presidente de la Cátedra L.S. Vygotsky de la Facultad de Psicología de La Universidad de La Habana con investigadores de América Latina y Europa, sistematizando los principios necesarios para una educación de calidad. 
Insistimos en esto porque los pensadores cubanos del siglo XIX postularon con claridad meridiana: 1) que la educación tenía que formar y desarrollar la conciencia y las facultades, como le decían entonces, en una unidad indisoluble, tal y cómo un siglo después, con el nombre de funciones psíquicas superiores explica más amplia, profunda y novedosamente, el enfoque histórico cultural y no de forma aislada o como cualidades independientes en sí mismas, como continúan defendiendo las ciencias más tradicionales, tales como el cognitivismo, las neurociencias y las lingüísticas; 2) insistían además, en que esas cualidades psíquicas, había que formarlas en el marco de la educación y no por medio de un entrenamiento aislado, repetitivo y mecánico; 3) que los métodos de enseñanza debían ser de manera tal que emplearan no solo, por ejemplo, la memorización mecánica sino, el proceso de pensar que hacía de esta, la memoria, una facultad o función más robusta y poderosa; 4) que era necesario formar virtudes y valores por medio de las artes, así como de las ciencias incluidas en los programas educacionales, y que no deben ser para descubrir o seleccionar talentos, sino para formarlos plena e integralmente y mucho menos, para detectar los escolares con dificultades de aprendizaje, sino para evitarlos. Y, esto es solo una mínima expresión del proximidad y analogía, que creemos que existe entre ambas concepciones, no obstante, sus diferencias (CABALLERO, 2001a, 2001b, 2001c; VYGOTSKY, 1987, 1995, 2001, ARIAS BEATÓN, 2015a, 2015b, 2017a).

Los pensadores cubanos del siglo XIX (MARTÍ, 1975; CABALLERO, 2001a, 2001b, 2001c), insistieron que las artes son vías para la formación de sentimientos y virtudes. Esto nos indica que no concebían una clasificación jerárquica, formal y excluyente de ninguna de las formas de producir conocimientos; por eso era legítimo que pensaran, como el humanismo iluminista que, con la labor educativa, se alcanzaría el desarrollo pleno e integral de la conciencia necesaria para formar al ser humano.

Estos pensadores señalaron, en su lucha anti escolástica, que la educación tenía que ser científica y de contenido científico, formadora de una conciencia crítica para luchar por liberar los pueblos del saqueo por parte de otros países. Esto fue una forma y ejemplo de destacar el carácter político que siempre tiene el saber científico en la formación de la conciencia social y crítica de los seres humanos y de los pueblos.

No creemos que haya sido casualidad que asumiéramos en medio de otro proyecto social revolucionario, la teoría o explicación del enfoque histórico cultural pues este posee, a diferencia de otras psicologías, una concepción humanista e integral, de una educación de calidad y para todos, como aquello que produce, conduce y arrastra el desarrollo psíquico y la formación de la conciencia como dijeran, también, los próceres cubanos en el siglo XIX. Incluso, declarando que esta contribuye al desarrollo de lo biológico, en el caso del ser humano. 
No es casualidad, por lo tanto, que nos apropiáramos de la teoría del enfoque histórico cultural, que un siglo después nos brindaba explicaciones más acabadas y científicas, que definitivamente contribuyera a las transformaciones y cambios necesarios que, a partir de finales de los años 60 del siglo pasado, necesito hacerse en parte de la educación cubana.

De esta manera, introduciendo los presupuestos del enfoque histórico cultural, en estrecha relación con las tradiciones culturales, filosóficas y educativas cubanas, fue posible elevar la calidad de la educación cubana, hasta los límites que nos ha permitido disminuir, hasta ahora, sensiblemente, el fracaso escolar y por lo tanto garantizar mejores aprendizajes y dominio de medios de la cultura como la escritura, el dibujo, el cálculo, los conceptos científicos y las artes. Esta historia y herencia une al grupo de autores de este artículo en sus esfuerzos y reflexiones, acerca de los desafíos y condiciones para una educación integral que resultaría en una educación escolar de calidad.

\section{DESARROLLO Y EDUCACIÓN EN SUS MÚLTIPLES DESAFÍOS}

En diversas comunicaciones orales y escritas Arias Beatón (2015a, 2015b, 2017a) ha mencionado que la educación de no calidad que predomina en el mundo, incluso para las élites, pudiera ser mejorada, si estudiáramos con profundidad, rigor y espíritu crítico, todo lo que se ha dicho y hecho para una educación de más calidad (JÄGER, 1995; COMENI0, 1983; STEVENSON; STIGLER, 1992; FARIÑAS LEÓN, 2007; FREIRE, 1971; MANACORDA, 2010), pudiéndose proyectar y garantizar para nuestras nuevas generaciones y a todos, sin discriminación, la educación, la enseñanza, el aprendizaje y el desarrollo psíquico y cultural que el ser humano merece, necesita y es posible, una formación más plena e integral. No obstante lo que plantea Engels (MARX; ENGELS, 1986), de que para garantizar los cambios revolucionarios deseados son necesarias grandes transformaciones estructurales en la sociedad, nosotros, mientras tanto, podemos ir creando las condiciones para que estas ocurran.

Considerando que, junto con el poder y extensión de los medios de propaganda y divulgación hegemónicos y alienantes, entre otros más inmersos en las sociedades actuales, han impactado en la objetivación de una educación de no calidad para todos, en muchos países, tenemos la hipótesis de que las vías políticas y educacionales que emplean los gobiernos actuales, permeadas por un discurso que invoca la democracia, buscan mantener a las personas, ajenas a la búsqueda de soluciones a sus malestares, inconformidades e incluso conseguir que, no obstante, éstas, las personas crean y se sientan conformes y adaptadas a las condiciones de la imperante injusticia social, las irracionales desigualdades y la burocracia autoritaria y corrupta que existe. 
El presente escrito, marcha a contracorriente de lo que predomina en el mundo de hoy, y se suma a las manifestaciones de luchas y de resistencias de la explotación y alienación históricamente instituida en la sociedad capitalista que nos afecta y molesta. Consideramos que es necesario avanzar en la organización de reuniones científicas y académicas con este sentido en el mundo. Sobre este aspecto, nos acercamos a cómo el mensaje y las explicaciones, aún inconclusas, que nos brinda el enfoque histórico cultural, pueden servir de contenido central para continuar sistematizándolo críticamente y conseguir la educación de calidad e integral que se necesita para todos.

Estas explicaciones pueden ser la base de ese proceso de sistematización crítica, porque es una de las concepciones más acabadas, integrales y generales que existen acerca del desarrollo psíquico humano, dado que ella es ya esa integración de la esencia del pensamiento filosófico, sociológico, biológico, pedagógico y psicológicos que se ha producido hasta ahora. Por eso, concibe una unidad indisoluble entre los procesos biológico, sociales y culturales en los que actúa el ser humano y contribuyen a la constitución de dicho desarrollo. Tal explicación posee esta característica, a su vez, porque presenta grandes contribuciones para lo que se ha producido en materia de educación y desarrollo humano desde los tiempos de Confucio, Sócrates y otros cientos de pensadores y educadores que siguen trabajando, por conseguir lo mejor que se ha producido en cuanto educación en la historia de la sociedad humana.

En el terreno de la psicología y la pedagogía comparada, deberíamos estudiar cómo el empleo de presupuestos teóricos, metodológicos y prácticos afines o análogos a los que postula el enfoque histórico cultural, han permitido resultados significativamente superiores en aquellos lugares donde se aplicaron o se aplican y en qué pueden contribuir de conjunto con este enfoque, a los propósitos que estamos formulando. El desenvolvimiento de investigaciones con tales finalidades serán necesarias para continuar con uno de los presupuestos metodológicos, prácticos y organizativos que nos planteó Vygotsky (1991, p. 259) desde los inicios, cuando en su plataforma programática dijo: "hay que trazarse un camino" e insistió, en la búsqueda de una educación de calidad y para todos, en la nueva sociedad que tendrá que existir algún día.

Vygotsky nos brindó explicaciones acerca del desarrollo humano y del papel de la educación que permiten revisar teorías producidas por la psicología desde el inicio del siglo XX. Entre ellas están el concepto del desarrollo de las funciones psíquicas superiores, el papel del otro, de la calidad de las relaciones interpersonales, de los niveles de ayuda, del papel de la vivencia, entre otros, como apunta Calejon (2012) en su análisis del enfoque histórico-cultural.

En este breve análisis, insistimos que el enfoque histórico cultural no es una panacea, ni es la solución de todo; el propio Vygotsky nos dejó una recomendación y un comentario que no debemos olvidar: "dudar de todo, criticarlo todo" (VYGOTSKY, 1991, p. 301). 
Esta es la clave de todo proceso de producción de conocimientos, dado que la historia de la humanidad nos ha mostrado que no llegamos a la verdad fácilmente, sino "cojeando". La verdad no surge a priori en las mentes "geniales" de algunos seres humanos, sino a posteriori como producto del trabajo histórico, la labor colectiva y social de decenas y cientos de generaciones de científicos y trabajadores orientados a hacer lo que creen mejor. Así es la historia, así es la ciencia, así son las artes, así es el proceso de producción de conocimientos, el quehacer social y de la cultura de los seres humanos y su historia.

Desde hace mucho tiempo, la formación y la educación que incluye a las artes y lo estético, conjuntamente con lo científico, filosófico, el deporte y la gimnástica, ha sido tratada con la perspectiva de que es la integralidad más genuina y por excelencia de lo bello, lo afectivo, lo cognitivo, lo físico y lo creativo humanos (JÄGER, 1995). Esta integralidad contiene lo emocional que es lo que determina las disposiciones humanas para las acciones, según Espinoza, idea retomada y desarrollada por Vygotsky (2004). Es la genuina relación indisoluble de lo afectivo, lo cognitivo y lo volitivo del quehacer humano. Todo esto es lo que, en última instancia, permite la formación y el desarrollo integral y su expresión personal, única e irrepetible en cada ser humano.

Lo humano, como afirma Shuare (2021), constituye un proceso de transformación compleja, es cultural, social, histórico y biológico, lo humano no es un espíritu puro, adscrito o inmanente, ni una producción biológica (genética o fisiológica) sólo; lo biológico humano tiene la propiedad y flexibilidad de adecuarse a lo social, cultural que le llega de la vida concreta del ser humano y de la educación que este recibe, garantizándose los aprendizajes y el psíquico humano correspondiente. Apenas nacemos con los contenidos psíquicos de naturaleza biológica semejante al resto de los seres vivos más evolucionados, pero tenemos la posibilidad, por contar con una biología lo suficientemente flexible y desarrollada para adecuarse a los contenidos sociales y cultural que son históricos, para poder transformar todas esas propiedades iniciales, en funciones de otra naturaleza y con otra estructura, que se constituyen por medio de la educación que incluye lo social y lo cultural que cientos de generaciones de seres humanos, que nos han antecedido, han producido (VYGOTSKY, 1987, 1995).

No somos una "tabula rasa"; pero, si la educación de la que estamos hablando, no se organiza, planifica y se consigue, la formación y desarrollo psíquico humano no superará, o superará solo parcialmente, las condiciones biológicas con las que nacemos y eso es fatal para la posible formación plena e integral del ser humano. Destacar esto es una forma de criticar y responsabilizar a las sociedades pasadas y presentes por los excesos cometidos en cuanto a una educación autoritaria, escolástica, fragmentada, centrada en el saber magnánimo del "educador" y, sobre todo, ajena al papel del vínculo afectivo del adulto con el 
educando que se desarrolla y aprende. Una Educación para formar mano de obra calificada o como hoy se insiste para el "hacer".

Quizás sea por todo esto que para la explicación histórico cultural, el estudio psicológico del arte haya sido un problema inicial, dirigido y orientado, definitivamente, a la búsqueda de una psicología diferente a la tradicional existente en su tiempo. El pensar el arte como un producto social, que contenga y exprese, los contenidos afectivos y cognitivos referidos a la vida real de las personas y los pueblos, y cuyo objeto es representar y, por esta vía, provocar experiencias personales que produzcan vivencias y sentidos, que conduzcan a la apropiación genuina e integral de la cultura humana en su mayor complejidad, es una de las vías de la educación para la formación y el desarrollo por el que abogamos en este trabajo.

Esto nos permiten presentar a las artes como una expresión insustituible de cómo se produce y se opera para promover esencialmente el desarrollo y la formación de la subjetividad o espiritualidad en el ser humano, o sea, su desarrollo psíquico. Es esta una enseñanza que debemos rescatar del conocimiento histórico cultural y que algunas comprensiones formales y materialistas no plenamente dialécticas que nos han influido, han ocultado, lentificado o retrasado su comprensión mas genuina.

Las artes en tanto que contienen en alto grado lo social, lo cultural, lo biológico y lo espiritual o subjetivo, lo emocional y lo cognitivos, se constituyen de hecho, en una actividad y en un contenido idóneo para estudiar el proceso psíquico en su esencia y actuar en consecuencia en pro de mejorar la formación y desarrollo integral del ser humano.

Las artes en cuanto producción humana socialmente constituida se relacionan con lo que dice Marx cuando habla del arte y de lo estético. Dice este autor:

\footnotetext{
[...] el animal construye solamente conforme con la medida y las necesidades de la especie a la cual pertenece, mientras que el hombre sabe producir según la medida de cualquier especie y en todas partes sabe aplicar al objeto la medida inherente; en virtud de esto el hombre construye también con arreglo a las leyes de la belleza. (MARX, 1973 p. 93 apud UBALS ÁLVAREZ, 2009, p. 97).
}

También consideramos que la producción humana en el campo del arte ha tenido lugar desde los albores de la humanidad cuando organizó sus formas de supervivencia, de manera rudimentaria. Como señalan Fontes y Bernardes (2020, p. 3):

[...] as pinturas rupestres inauguram as artes plásticas, e os rituais que envolviam movimentação corporal alinhada à emissão de sons constituem 
uma forma de performance dramatizada. Não à toa que estudiosos do teatro, da dança e da música se referem a esses rituais como o possivel princípio da expressão dessas artes, que datam do período pré-histórico, cada qual identificando e analisando os aspectos que lhes são próprios. Essas manifestações não podem ser encaradas como simples atos que nada representam para a história do desenvolvimento da humanidade, mas sim como constituintes desse desenvolvimento.

El arte y la belleza creadas por el ser humano, a partir de su vida real, lo acompañan desde las pinturas rupestres y las formas iniciales de educación; estos contenidos se incluyeron desde bien temprano en el proceso de la producción histórica, conjuntamente con los del hacer tecnológico, la escritura y el pensar, en el proceso complejo de producir la cultura y con ello y en ella, producir lo específicamente humano, la subjetividad o desarrollo psíquico humano. Ello nos indica el papel tanto de lo uno como de lo otro en este proceso complejo y dialéctico del desarrollo y su educación en el proceso histórico de la cultura.

Es por eso que podemos afirmar que, si el ser humano recibe la educación y formación que necesita y merece, en él pueden llegar a existir formas de expresión de la subjetividad muy apreciadas tales como el sentir, crear, pensar, explicar críticamente y producir no solo objetos e instrumentos útiles, sino cosas imaginadas, creadas y recreadas con belleza, extraídas y combinadas con las bellezas de la naturaleza y de su existencia.

El arte como manifestación de la subjetividad humana sobre la realidad es objetivado por la praxis creativa que produce cambios, que promueven transformaciones (VÁZQUEZ, 2007). Estos cambios y transformaciones en la formación humana y en realidad están vinculados a la calidad de la educación dependiendo de las condiciones materiales e inmateriales definidas por la organización social.

Por todo esto es que insistimos en subrayar que el pensamiento y la obra escrita del enfoque histórico cultural y su teoría, no solo pueden contribuir a mejorar la educación en el mundo actual, sino lograr la formación integral y plena que deseamos para el ser humano.

\section{LAS ARTES Y LA EDUCACIÓN COMO LAS FUENTES ESENCIALES DEL DESARROLLO PSÍQUICO HUMANO INTEGRAL}

La Nota a la Edición Cubana del libro Imaginación y Creación en la Edad Infantil (VYGOTSKY, 1987) en el marco de un intento por crear una educación integral y de calidad para todos, da cuenta del valor que tuvo y tiene esta obra para que los profesores y familiares llevarán a cabo con más calidad su labor educativa, trabajando la imaginación y la creación, 
el arte y la educación estética como un componente esencial de esa educación en la que pensamos para todos las personas en este mundo. Dice la Nota que encabeza este libro:

\footnotetext{
El estudio sobre la creación plástica infantil y otras esferas del arte, tratado en este libro, se vale de las ideas reinantes en la psicología de la época. Las concepciones fundamentales explicadas por el autor, cuyas teorías nacieron a partir de dicho estudio, tienen gran validez y autenticidad científica para la ejercitación y el desarrollo de la imaginación, las cuales se consolidan en el proceso creativo futuro.

En la década de los años 20 era común esgrimir la tesis de la espontaneidad en las creaciones infantiles; sin embargo, las investigaciones de L. S. Vigotsky constituyeron un aporte esencial al cultivo de la creación e imaginación en la edad escolar, y no han sido limitadas por la evolución sociohistórica, sino que continúan vigentes en nuestros días.

Imaginación y creación en la edad infantil está destinado a los institutos superiores pedagógicos y concebido como un pequeño ensayo de divulgación científica para padres y maestros. (VYGOTSKY, 1987, p. 1).
}

Vygotsky trabajó esencialmente, en el capítulo 13 de Psicología Pedagógica, Un Curso Breve (2001, p. 355-394), un minucioso análisis crítico y metodológico acerca del papel de la educación estética a través del arte, en la formación y desarrollo psíquico humano. También en el libro Imaginación y creación en la edad infantil (VYGOTSKY, 1987), amplía estos aspectos esenciales. Quizás su muerte prematura no le permitió, después delinear y producir importantes explicaciones para una nueva psicología, volver sobre estos pasos y profundizar o sistematizar sus hipótesis iniciales sobre el arte, la educación estética y su papel en el desarrollo y formación psíquico humano, labor que aún está por realizarse. Sirva este escrito para seguir pensando y trabajando en esta honrosa tarea a la luz de los propósitos de lograr una formación integral y plena del ser humano.

Las ideas de Vygotsky no son exactamente las ideas de los pensadores que lo antecedieron o fueron sus contemporáneos, sino el producto de estudios y análisis críticos e integradores de lo que éstos dijeron; él dialoga, intercambia y colabora con ellos, con el objetivo de contribuir a la producción de nuevos y más acabados conocimientos. Se trata de un genuino proceso histórico y cultural de intercambio y colaboración social y colectiva con generaciones y grupos de pensadores y científicos. El compromiso de Vygotsky es con el ser humano, con su buena educación, aprendizaje, formación y desarrollo.

Por todo ello cobra una gran importancia lo que afirmara Manacorda $(1980,2010)$ en su escrito sobre la Pedagogía de Vygotsky al decir que la humanización de la pedagogía, su liberación de la cautividad biológica para convertirse en humana e histórica: éste es el centro y la inspiración fundamental de la obra de Vygotsky. 
No es casual, por lo tanto, que para Vygotsky el arte, la educación estética; el desarrollo y la formación de la imaginación creadora sean un contenido esencial de esa educación que arrastra y produce el desarrollo psíquico humano, contribuyendo al desarrollo integral que defendemos.

Vygotsky comienza su análisis acerca de la educación estética, presentándonos el estado en que ésta se encontraba en su época.

Si bien sería de mucho interés estudiar cómo, en la actualidad, se considera la naturaleza, el significado, los objetivos y los métodos de la educación estética y compararlos con el análisis que hizo Vygotsky; la situación actual parece que no dista mucho de los problemas que él señaló. Lo más significativo es que muchos de esos males se pueden ver multiplicados, dado el desarrollo de los medios tecnológicos, de divulgación y comunicación y el enorme proceso de mercantilización al que se han sometido dichos contenidos y medios culturales, no obstante, los que luchan en contra de esa banalización de la cultura y el arte.

Los productos del arte infantil, en su inmensa mayoría, se caracterizan por los males que Vygotsky señaló, y lo más relevante, es que los objetivos se limitan al goce y al entretenimiento, al control del comportamiento, y en el mejor de los casos al "reforzamiento" del desarrollo mecánico y memorístico de los procesos naturales.

No son pocos los casos de niños que en edades tempranas e incluso desde bebés, han sido usuarios habituales de estos entrenamientos en solitario. Ellos llegan a adquirir, muy rápidamente, síntomas autistas, tales como la ausencia de vínculos y comunicación con los demás, la ausencia de un lenguaje articulado y serias dificultades en los procesos de atención y concentración. Por suerte, comienzan a aparecer las alertas y los reportes de algunos profesionales contra estas inadecuadas prácticas educativas.

Estas prácticas nos brindan una prueba excepcional de lo importante, sano, esencial y necesario que resultan las relaciones sociales entre el recién nacido, el bebé o el niño con los adultos y los coetáneos más desarrollados (VYGOTSKY, 1988), sobre todo la necesidad de que estas relaciones lleguen a conformar verdaderos vínculos emocionales o afectivos, para que estos se conviertan, a su vez, en la disposición, la motivación y la vía ancha por la cual los adultos pueden promover y garantizar el sano, superior e integral desarrollo psíquico humano (VYGOTSKY; LURIA, 2007). Esto también nos hace recordar los estudios de Spitz $(1945,1946)$ sobre el efecto de las carencias afectivas y de las relaciones o vínculos entre los niños y los adultos. Lo que este autor, desde otra base epistemológica, sistematiza el concepto de organizadores y refuerza el papel de las relaciones sociales o interpersonales en el desarrollo psíquico humano.

La educación estética, por todo lo señalado y según lo que podemos extraer de sus análisis, fue considerada por Vygotsky un proceso de naturaleza social, cultural e 
histórico que tiene como objetivo y fines concretos, promover la formación y desarrollo de la apreciación estética de las obras creadas por los seres humanos a partir de los elementos que nos brinda la naturaleza y la sociedad. Es un producto de los procesos de apropiación y acumulación de la experiencia personal del sujeto, que le permiten combinar, crear y recrear, a partir de las imágenes formadas, nuevas experiencias, objetos y situaciones que se expresan en nuevos productos de creación. De hecho, se constituye en bases para el desarrollo más pleno e integral del ser humano.

La educación estética en su sentido más amplio, en esencia, se realiza por medio del quehacer educativo general que se organiza y produce en la escuela, en la familia y en la comunidad, pero con actividades específicas como son: observar la naturaleza, promover las creaciones infantiles, dibujar, jugar, pintar, realizar bailes, escuchar música, hacer relatos y cuentos, leer poesías, interpretarlas; promoviendo y estimulando en todas estas actividades las buenas y bellas formas de sentir y hacer.

El desarrollo de las disciplinas de conocimientos filosóficos, históricos, técnicos o laborales y científicos, en un programa de educación de calidad, integral y pleno, deben impartirse en una unidad indisoluble, con las disciplinas de la educación estética, la educación física y el deporte, que también tienen que ver con la buena y bella salud física de los seres humanos.

La utopía de la integralidad de la educación, nos viene desde el ideal espiritual que debía formar la educación o Paideia griega que, aunque insuficientemente concebida en término de la participación de todos los seres humanos, se constituye en el inicio de una utopía defendida con elegancia y valor científico por Vygotsky. Ello sigue siendo un ideal que debemos seguir trabajando hasta alcanzarlo definitivamente, mucho más temprano que tarde, en la sociedad humana (JÄGER, 1995; VYGOTSKY, 2001).

No obstante, lo positivo que se pueda extraer de los estudios y análisis que sobre la educación estética hace Vygotsky, él hace algunas críticas sobre ciertas concepciones y prácticas inadecuadas, a las que nos queremos referir brevemente, dado el gran valor metodológico y práctico que tienen para la labor educativa y pedagógica en todos sus planos y niveles.

Vygotsky (2001), criticando a aquellos que piensan que solo por medio de las obras de arte se pueden enseñar acciones morales, conocimientos sociales y científicos, insiste que esta educación puede, si se emplea para estos fines, producir conocimientos insuficientes o deformados sobre la moral, la historia y sobre una realidad dada. Esto se debe a que la obra de arte, si bien es creada a partir de las experiencias acumuladas en las relaciones con una determinada realidad, son en última instancia, el producto de los sentimientos y emociones que dicha realidad produce. En la relación estética del sujeto con esa realidad existe una 
mayor dosis de subjetividad humana, de visión y sentir más particular, en comparación con la relación científica y moral de un determinado conocimiento a partir de esa misma realidad.

Teniendo en cuenta esta situación en la producción de conocimientos y la enseñanza, Vygotsky nos alerta, a no solo tener conciencia de ello, sino a emplear los conocimientos científicos y los que se derivan de las obras de arte, en una unidad inseparable, pero según los fines y propósitos de la educación que deseemos realizar y tengamos que garantizar.

En este complejo análisis, Vygotsky (2001) insiste que en las disciplinas históricas o sociales y de la naturaleza, así como en la formación práctica de las acciones morales, el sujeto debe aprenderlas, por medio de materiales científicos, producidos según los estudios correspondientes y elaborados para explicar el hecho social, el objeto o el hecho específico.

De la misma forma, señala que la mejor manera de educar la moral es mediante las prácticas concretas de las propias acciones y los ejemplos de las prácticas correspondientes y no de lecciones formales, dogmáticas o autoritarias. Él insiste en que cada tipo de contenido específico de la enseñanza y la educación necesita de contenidos, métodos y procedimientos peculiares para que sean correctamente apropiados por parte del educando.

Sin embargo, en un momento determinado de su análisis crítico, para nosotros, producto del análisis dialéctico certero de las contradicciones o situaciones complejas a la que nos tiene acostumbrado, Vygotsky destaca que si bien las obras de arte no se deben emplear directamente para explicar científicamente los hechos y el conocimiento en general, cuando éstos ya se poseen o se dominan, la obra de arte sí puede de manera indirecta, brindar conocimientos complementarios a aquellos conocimientos esenciales y científicos que se posean, ampliándolos en el sentido estético y más complejo. Esta forma de hacer, a nuestro juicio, enriquece tanto lo científico, como lo que contiene el arte sobre estos hechos y es una forma de integrar lo diverso en su unidad.

Vygotsky habla de que los caminos pedagógicos y educativos son para uno directo y para el otro indirecto. $Y$ que lo estético ha de educarse por medio de las artes $y$, una labor artística y creadora y, los conocimientos científicos generales y la moral, han de enseñarse por medio de las disciplinas científicas las primeras y de las prácticas educativas las segundas, en una unidad inseparable.

Este análisis tiene un valor metodológico esencial para comprender que la labor educativa y pedagógica; no debe ser fortuita o no intencional, sino el producto de una concepción integral, adecuada y consciente del papel que posee cada acción pedagógica, de la enseñanza y la educación que se realiza. De cómo organizar los contenidos específicos de que se trate y según los propósitos y objetivos de dicha educación. 
Todo esto implica el importante reconocimiento de que toda obra de arte es una representación de la realidad, pero no es una copia fiel, porque aunque se deriva y nace de ella, se encuentra mediada esencialmente por los sentimientos, emociones, intereses, gustos e historia social y cultural del desarrollo psíquico de los sujetos que la producen o reproducen; lo que se constituye en una de las características esenciales de los productos específicamente humanos, o sea de lo espiritual, subjetivo o psíquico humano.

Las obras de arte, aunque no explican directamente la esencia de los hechos que deben ser científicamente aprehendidas, abordan aspectos interesantes y necesarios de resaltar, con vistas al conocimiento directo de lo estético, y lo indirecto del resto de los conocimientos.

La Divina Comedia de Dantes de Alighieri (1304 - 1321), la Comedia Humana de Honorato de Balzac (1945 - 1953), el Guernica de Pablo Picasso (1937), el Mural de la Guerra y la Paz de Cándido Portinari (1957) y la Cecilia Valdés de Cirilo Villaverde (1839), por ejemplo, nos permiten apreciar situaciones, características, descripciones, símbolos, que recrean la época o los hechos y sus características; ilustrando los conocimientos científicos, actitudinales y morales, pero sobre todo, lo consigue, a partir de la visión, los intereses, motivos, gustos, concepciones e historia personal del autor y también del que aprecia la obra.

Las obras de arte sirven sin dudas, como señala Vygotsky, de manera indirecta para complementar elementos significativos de una época o de situaciones y hechos que representan, pero ello no es un estudio sistemático y científico que nos permita la explicación esencial de una época, de un hecho o de un objeto de estudio determinado.

La Comedia Humana de Balzac (1945 - 1953) muestra o describe como pocas, las relaciones entre la sociedad y las características psicológicas de los personajes de su época, sin embargo, no es conveniente estudiar y explicar la psicología de las personas, el papel de lo social y lo cultural en el desarrollo psíquico por medio de ella.

Los comentarios del hijo de Portinari, son un ejemplo de esto que decimos y nos develan el sentido que podemos llegar a atribuirle a una obra de arte y en lo que esta puede contribuir, como tal, a la educación, el conocimientos y el desarrollo y la formación de valores y virtudes estéticas con conocimientos en general, diríamos más integral de lo que representa la obra, en el ser humano. Dicen Jorge Miyares e Rocio Franco (2015), sobre la obra de Portinari:

Hay dos cosas que llaman mucho la atención cuando uno ve los murales de 'Guerra y Paz'. La primera es que Portinari no pintó armas, no hay ametralladoras, no hay tanques, ni uniformes, ni soldados. Es una obra que no tiene fecha. Representó a la guerra a través del sufrimiento de la población civil, principalmente con la madre que pierde a su hijo, es el 
personaje más fuerte del panel de la guerra, se ve ocho veces, es la representación clásica de la Piedad, dijo.

Jorge Miyares e Rocio Franco (2015) también destacan los colores en la obra de Portinari: "L... que describieron como sorprendentes, porque no existe la costumbre de pensar en la guerra en un tono azul y afirmaron que más que la guerra y la paz, las pinturas materializan el bien y el mal."

Este ejemplo, su lectura nos sugiere un quehacer metodológico, didáctico y educativo, que implica que después de la experiencia vivida (vivencia) producida por la observación y la contemplación de una obra como la mencionada, se puede promover un debate entre los estudiantes, esencialmente adolescentes y conseguir que se expongan los sentidos atribuidos a esa obra y por qué se viven de esa forma, lo que puede contribuir a formar en los estudiantes, actitudes, ideas e intereses sobre lo representado y lo estéticos, para poder apreciar lo real y concreto de la vida, además, de lo creativo, original y bello de la obra de arte de que se trate.

Actividades como estas contribuyen a que los estudiantes puedan apreciar cómo un autor $\mathrm{u}$ otro, consigue expresar en sus creaciones artísticas una visión estética de la realidad, además de expresar sus interpretaciones de los hechos históricos o científicos en ella inmersos.

Esto hace que la educación artística, llegue a tener el propósito específico de producir una verdadera educación plena e integral, estética, encaminada a preparar al ser humano para apreciar lo bello y las formas de conseguirlo según el empleo y la creación y recreación de los elementos de la realidad. Vygotsky (2001, p. 368) dice al respecto:

\footnotetext{
[...] Y solo si emprendemos este camino podremos comprender el valor cognoscitivo, moral y emocional del arte. Todo esto, sin duda alguna, puede existir, pero siempre como componente secundario, como una suerte de secuela de la obra de arte que no surge de otro modo que inmediatamente después que se ha cumplido por completo la acción estética.
}

Es esto precisamente lo que se habla de la obra de Portinari, que nos refiere en esa secuencia; primero insiste en lo que expresa la acción estética del mural y posteriormente el valor cognoscitivo y moral que se puede desprender de esa obra o lo que ella representa, según la imaginación creadora del autor, incluido lo bello que porta.

Esta obra de arte no nos explica exhaustivamente el por qué y el para qué se producen las guerras o cuáles son sus consecuencias. No obstante, proporciona esenciales conocimientos complementarios y sobre todo hace vivir de manera conjunta, emocional y 
sentimentalmente, lo que producen las guerras como hecho histórico e inhumano. El por qué, el para qué y las consecuencias que producen las guerras, entre otros conocimientos a adquirir, son los contenidos propios de las ciencias sociales e históricas. Esta es gran parte de la razón de la importancia de una educación que tenga en cuenta la plenitud e integralidad que demandamos que algún día tenga la educación en todo el mundo y para todas las personas.

Estos son los caminos e intentos de la explicación científica de las artes en la educación y el desarrollo psíquico humano de Vygotsky, que muestran de inmediato su gran valor didáctico para el empleo de las artes en la formación integral del ser humano. Deseamos mostrar con insistencia esto, dado el gran interés y la preocupación de estudiosos e investigadores sobre la Educación desarrolladora en Cuba y en Brasil, y que luchan por una educación plena e integral de calidad.

Estos especialista y científicos trabajan por seguir los pasos de la producción de una didáctica desarrolladora, según investigaron autores como Elkonin y Davidov, entre otros, siguiendo las explicaciones, leyes y postulados de Vygotsky y sus colaboradores en un inicio, aunque aún, no obstante, los esfuerzos que se han realizado, según lo que señalan Elkonin (1984, 2017) y Davidov (1988), se necesita una mayor sistematización crítica para conseguirlo.

No podemos dejar de insistir, en este análisis, en algo que creemos representa una alerta esencial y que la mercantilización ha exacerbado en nuestros tiempos. Nos referimos a las tendencias de presentar la obra de arte como aquello que produce, esencialmente, sentimientos de goce, placer y diversión, reduciendo la vivencia estética a producir un efecto hedonista y con ello alejar al sujeto de su valor educativo esencial, lo estético y lo bello del quehacer humano. Por eso dice Vygotsky (2001 p. 361) “Quien piensa cultivar la estética en la educación como fuente de placer, se arriesga siempre a encontrar en la primera golosina y en el primer paseo, los más fuertes competidores."

A nuestro juicio, este es uno de los grandes problemas que se le presentan a la Pedagogía y a la Psicología en las sociedades alienantes en las que hoy vivimos: ¿̇qué hacer para que la educación artística y estética sean verdaderamente humanistas y formadoras del ser humano, contribuyendo a una formación plena e integral de las personas?

Para Vygotsky, como para muchos otros pensadores a lo largo de la historia de la cultura humana, el valor esencial de la educación estética es la formación y el desarrollo de cómo apreciar la belleza y promover la originalidad creativa. Es una forma de educar y formar el sentir y el apreciar donde existe esta belleza. Por eso es que Vygotsky en su análisis, insiste como también, insistieron los iluministas y humanistas (DIDEROT; D'ALEMBERT, 1889), que ya nos alertaron de la exacerbación de las tendencias hedonistas en los seres humanos y en la aristocracia en particular, diciendo: "[...] Evidentemente, la obra de arte no se percibe 
con una total pasividad del organismo, ni solo con los oídos o los ojos, sino mediante una complejísima actividad interna en la que la vista y el oído son solo el primer paso, el envión, el impulso básico." (VYGOTSKY, 2001 p. 362).

Y continúa, citando a Christiansen sobre lo esencial del proceso de apreciación estética del arte que hay que formar y educar de una manera intencional y consciente en nuestra educación. Dice Vygotsky (2001 p. 362) “El entretener nuestros sentidos no es el objetivo final del proyecto artístico. Lo principal en la música es lo inaudible; en las artes plásticas, lo invisible e intangible."

Y termina con su análisis esencial, diciendo: "Pero estas influencias sensibles están organizadas y construidas de tal manera que despiertan en el organismo un tipo de reacción distinta del habitual, y es esta actividad peculiar, vinculada a los estímulos estéticos, lo que constituye la naturaleza de la vivencia estética." (VYGOTSKY, 2001 p. 363).

A partir de todo esto es que podemos apreciar lo que se constituye en la naturaleza, los objetivos, el contenido y algo de la metodología básica para garantizar por medio de las artes, la educación y el desarrollo de la estética, la imaginación creadora y lo mejor de las virtudes humanas, para que se contribuya a que en el estudiante se formen las posibilidades de apreciar, sentir e interpretar una obra de arte, sus valores estéticos, sus méritos de contener aspectos esenciales y particulares de cualquier hecho u objeto que represente y además, todo ello entonces, se constituya en una manera de sentir el disfrute y expresión de nuestros sentimientos y emociones cuando estamos ante una obra de arte.

No es que la obra de arte no nos produzca goce o placer, eso es muy importante y esencial, es que ella nos lo produzca cuando seamos capaces de apreciar y vivir, la vivencia estética atribuida de sentidos e incluso de apropiarnos de los conocimientos, sentimientos y emociones que ella contiene y produce en cada observador $y$, entonces, como un producto o resultado de todo esto, la persona sienta el placer de ello.

Deseamos, ahora, señalar otro aspecto esencial que aborda Vygotsky. Para este autor las fábulas y los cuentos infantiles son uno de los medios más importantes para promover la educación estética de los niños. Hoy los comics o tiras filmicas pretenden sustituirlos, pero en realidad solo lo hacen de manera formal y con el objetivo del entretenimiento y control del comportamiento. No creemos que su empleo, en la mayoría de las producciones, favorezca la educación estética. Los cómics de hoy han heredado de manera superlativa los errores y excesos que tenían, en la época de este autor que estamos estudiando, los cuentos infantiles. Hoy en día además de las fantasías tontas y superficiales, se les han agregado las acciones agresivas, violentas, racistas y discriminadoras, mecánicas y meramente reproductivas, entre otras, que los promotores de estos medios de recreación se empeñan en hacer creer que es lo que los niños necesitan, desean, comprenden mejor y los desarrollan. 
Vygotsky señala con mucho acierto que la causa esencial de las exageradas deformaciones que sufre la realidad en los cuentos infantiles es un producto de la incomprensión de cómo se produce el desarrollo psíquico infantil. Hoy se le suma a esa incomprensión, la necesidad de producir un mercado lucrativo que haciendo lo que hace, consiga entretener y controlar el comportamiento de la manera más elemental, primitiva y efectiva que se pueda, pero que no produce el posible y necesario desarrollo psíquico de las niñas y niños.

A partir de los análisis de las deformaciones que sufre la realidad en los cuentos infantiles y el daño que eso puede producir en la psiquis infantil, postula también con mucho acierto, incluso muy válido en nuestros días que, "[...] la verdad debe convertirse en el fundamento de la educación desde la más temprana edad." (VYGOTSKY, 2001 p. 380).

Por esto censura fuertemente las prácticas exageradas de deformación de la realidad afirmando: "Por todo esto debemos convenir con el criterio que demanda eliminar absoluta y completamente esas nociones fantásticas y necias en las que se suele educar al niño." (VYGOTSKY, 2001 p. 381).

Conjuntamente con estos males dice, además: se abusa, como se hace hoy todavía, del empleo del lenguaje deformado por los adultos, para supuestamente adecuarse más al uso que hace el niño del lenguaje oral. Señala Vygotsky, con mucho tino, que el adulto no sabe que el niño pronuncia así, no porque lo desea u oye así, sino porque aún no puede hacerlo de la manera correcta, dado su desarrollo; e insiste, en que esas deformaciones que produce el adulto, sí se convierten en un modelo de lenguaje oral, puede dañar el desarrollo futuro, dado que el niño aprende a emplearlo de manera deformada.

No obstante, estos males, relacionados con el cuento infantil, Vygotsky se vuelve a preguntar si este no pudiera ser creado o producido de otra forma, que pueda ser más claro, asequible y con una fantasía suave y bella que contribuya a la educación tanto estética y emocional, como social, cognitiva y moral.

Hacemos extensivo esto también a los cómics, porque observamos con mucho detenimiento y satisfacción, los intentos y tendencias, cada vez más crecientes, de producir este tipo de cuentos ligeros, con valores estéticos mejores, que los que aún inundan los medios de difusión y recreación cultural.

Insiste Vygotsky (2001) en lo esencial, en lo que ya postula en Psicología del Arte (1972) y luego más tarde en Imaginación y creación infantil y en lo que nos hemos detenido en varios momentos de esta exposición. Señalando: 
la estética borra toda frontera que separa lo fantástico de la verdad. En el arte todo es fantástico y todo es real, porque todo es convencional, y la realidad del arte implica solo la realidad de las emociones que están vinculadas con el mismo. (VYGOTSKY, 2001 p. 383).

Y, por último, recomienda, como para evitar las deformaciones exageradas y grotescas de la realidad, lo siguiente: "[...] No apartamos en absoluto a los niños de la realidad cuando les contamos un cuento fantástico con la sola condición de que los sentimientos que surgen al hacerlo estén de cara a la vida." (VYGOTSKY, 2001 p. 383).

Un ejemplo de esto, a nuestro juicio, son los cuentos que introdujo José Martí en su publicación en forma de cuadernos para los niños, que llamó la Edad de Oro, en el siglo XIX, donde lo real, lo fantástico y estético se combinan con tanta maestría que, como dice Vygotsky, resulta dificil olvidar las emociones sentidas y los conocimientos adquiridos 0 sea, las vivencias ${ }^{5}$ estéticas y sus sentidos atribuidos a esos cuentos y a las experiencias que nos produjeron; que aun en la adultez continúan produciéndonos nuevas vivencias y reacciones emocionales típicas y reales y los recordamos como conocimientos significativos de nuestras vidas (MARTí, 1997).

Por eso, para nosotros es totalmente acertado lo que afirma Vygotsky (2001 p. 383) "L... la única justificación para una obra fantástica es su base emocional real y no nos asombrará reconocer que, con la eliminación de lo fantástico nocivo, el cuento siga siendo, de todos modos, una de las formas del arte infantil."

Otra expresión de esta ley sobre la realidad emocional, vinculada a la vida real del sujeto, que ha de guiar la producción de la fantasía, dice Vygotsky, en estos trabajos tempranos, que el cuento y el juego son muy próximos en su papel desarrollador de la psiquis infantil. Por eso señala: "En el juego, el niño siempre transforma creativamente la realidad [...]" (VYGOTSKY, 2001 p. 384) y concluye con una idea importante que seleccionamos para concluir estos análisis conceptuales y metodológicos de la educación estética en la educación plena e integral: Dice Vygotsky (2001 p. 385) "Un cuento artístico lo mismo que el juego, es el educador estético natural del niño."

No hay educación estética sin una unidad indisoluble con la educación en general y científica, con el deporte, la Educación Fisica y con la formación politécnica y laboral, que definitivamente conforman la esencia de la plenitud e integralidad de la educación de calidad para todos de la que hablamos y que extraemos de la Teoría y del Enfoque Histórico Cultural

5 Toda vivencia al ser la unidad funcional básica de lo psíquico humano (Vygotsky le llamó unidad de análisis), es la unidad más sencilla de lo psíquico humano que contiene todos los elementos que conforman dicha cualidad, o sea, lo afectivo, lo cognitivo, lo consciente y lo inconsciente, lo biológico, lo social, lo cultural, lo individual y lo grupal, el medio y la personalidad, entre otros componentes o determinantes mediadores y productores del desarrollo psíquico humano (VYGOTSKY, 1996; ARIAS BEATON, 2017b; FARIÑAS LEÓN; CARNIELO CALEJON, 2017). 
como la síntesis más científica y bella creada hasta hoy a partir de lo mejor que se ha producido en la sociedad y en la cultura humana sobre el desarrollo pleno e integral del ser humano.

Creo que esta explicación, incluye todas las luchas y todo lo producido sobre el tema de la educación integral y de calidad, por la que seguimos trabajando y que aún no existe; desde los tiempos de la Paideia hasta la actualidad. Este es el gran mérito histórico y científico de esta Teoría, más allá de lo que aporta específicamente, en el conocimiento del desarrollo psíquico humano.

\section{A MODO DE CONCLUSIONES}

Estas son solo algunas pinceladas de nuestros sueños y deseos que habrá que continuar explorando, probando y materializando en las prácticas pedagógicas y educativas en el mundo actual, para alcanzar algún día, cuando disfrutemos de una sociedad diferente, de los resultados deseados que en este escrito señalamos.

Solo una educación y una enseñanza de la mayor calidad posible hace verosímil un desarrollo pleno e integral del ser humano. No son los vacíos y abstractos discursos y las políticas públicas escritas, las que lo lograrán, sino, aquel quehacer que se realice según los fundamentos que hemos intentado sistematizar sintéticamente en este trabajo.

Los fundamentos, principios e incluso aspectos metodológicos e instrumentales de cómo se ha de trabajar una educación de calidad para que sea verdaderamente desarrolladora y la validez, se mencionan y existen desde los tiempos de la Grecia esclavista y han sido ampliados por numerosos pensadores a lo largo de la historia cultural de la humanidad.

Conocimientos científicos y técnicos no faltan, lo que sucede es que no han sido propiedad de todos los seres humanos, dado al abandono al que las sociedades de explotación han mantenido y mantienen a los pueblos que deberían disfrutar de esa educación en el mundo.

La educación de calidad, ha de ser integral por lo que ha de incluir el conocimiento de las ciencias, de las artes, del deporte y del quehacer humano que de estas disciplinas se desprende, de las tradiciones y costumbres culturales de los pueblos. No es solo insistir en una preparación técnica para garantizar una labor productiva, economicista y lucrativa solo para unos pocos, sino, para la producción de riquezas que todos los seres humanos puedan disfrutar para poder vivir con independencia y decoro, de forma humanista. 
Por eso partimos en nuestro análisis, de la idea que se expresa en el epígrafe que guía este trabajo, dicho por Martí, Héroe y Apóstol cubano que murió en combate, luchando contra las tropas extranjeras que mantenían el colonialismo en Cuba en el siglo XIX. El aislamiento del arte, o su inadecuado empleo en la educación, conducen al riesgo señalado por Martí de generar una educación de fundamentos estrechos, fragmentados y reduccionistas sobre el desarrollo humano, tal y como, aquellas que hacen una ruptura de la dimensión cognitiva y afectiva, de la razón y las emociones, sobrevalorando la razón y deformándola, porque ella no existe aislada, sino que incluye y depende su calidad de la integralidad que defendemos.

Llegar a una educación plena exige eliminar estas dicotomías desde el punto de vista teórico y práctico, encontrar los nexos y relaciones, de hecho, revisar también, las políticas públicas de la educación y sus direcciones ideológicas, lo que en el presente trabajo hemos intentado mostrar, cómo hacerlo.

Los ejemplos prácticos y políticos que nos muestra lo realizado por los pensadores cubanos del siglo XIX y lo que se hizo introduciendo solo algunos de los fundamentos esenciales del enfoque histórico cultural en la educación cubana, han sido un punto de partida para este trabajo.

\section{REFERENCIAS}

ARIAS BEATÓN, G. Contribuciones de los cubanos a lo histórico cultural. Un debate constituyente. Alternativas cubanas en Psicología, v. 3, n. 7, p. 13-24, 2015 a.

ARIAS BEATÓN, G. Desarrollo histórico de los escolares con necesidades educativas especiales. Apuntes y consideraciones. In: COLECTIVO DE AUTORES (org.). Psicología Especial T. 1. La Habana: Editorial Félix Varela, 2005a. p. 1-18.

ARIAS BEATON, G. La educación inicial y preescolar, la función simbólica y el signo en el desarrollo psíquico humano. In: ARIAS BEATÓN, G.; FARIÑAS LEÓN, G.; PEDROL TROITEIRO, R. (org.). Enfoque histórico-cultural: otros problemas de las prácticas profesionales. São Paulo: Editorial Terracota, 2017a. v. 3, p. 257-277.

ARIAS BEATÓN, G. La persona en el enfoque histórico cultural. São Paulo: Linear B, 2005b.

ARIAS BEATÓN, G. Los aportes del enfoque histórico cultural y la educación cubana. Revista diálogos e perspectivas em educação especial, v. 2, n. 2, p. 23-38, jul./dez. 2015b. 
ARIAS BEATÓN, G. Vivencia, atribuição de sentido e subjetivação da atividade, a comunicação e relações sociais. In: BERNARDES, M. E. M.; ARIAS BEATÓN, G. (org.). Trabalho, Educação e Lazer. Contribuições do Enfoque Histórico-Cultural para o desenvolvimento humano. São Paulo: Escola de Artes, Ciências e Humanidades, 2017b. p. 143-214.

BERNARDES, M. E. M. Mediações simbólicas na atividade pedagógica: contribuições da teoria histórico-cultural para o ensino e a aprendizagem. 1. ed. Curitiba: Editora CRV, 2012.

CABALLERO, J. de la L. Obras: aforismo. La Habana, Cuba: Ediciones Imágenes Contemporáneas, 2001a. v. I.

CABALLERO, J. de la L. Obras: elencos y discursos académicos. La Habana, Cuba: Ediciones Imágenes Contemporáneas, 2001b. v. III.

CABALLERO, J. de la L. Obras: escritos educativos. La Habana, Cuba: Ediciones Imágenes Contemporáneas, 2001c. v. Il.

CALEJON, L. M. C. Desenvolvimento humano: uma reflexão a partir do enfoque histórico-cultural. In: LIMA E DIAS, M. A.; FUKUMITSUK, 0.; MELO, A. F. T. (org.). Temas contemporâneos em psicologia do desenvolvimento. São Paulo: Vetor, 2012.

COMENIO, A. J. Didáctica magna. Ciudad de la Habana, Cuba: Editorial Pueblo y Educación, 1983.

DAVIDOV, V. V. La enseñanza escolar y el desarrollo psíquico. Moscú: Editorial Progreso, 1988.

DIDEROT, D.; D'ALEMBERT, J. le R. Discurso preliminar e outros textos. In: DIDEROT, D. et al. Enciclopédia ou dicionário raciocinado das ciências das artes e dos oficios por uma sociedade de letrados. São Paulo: Editora UNESP, 1989.

ELKONIN, D. B. Psicología del juego. Ciudad de la Habana, Cuba: Editorial Pueblo y Educación, 1984.

ELKONIN, B. D. Sobre o problema da periodização do desenvolvimento psiquico na infância. In: LONGAREZI, A. M.; VALDÉS PUENTES, R. (org.) Ensino desenvolvimental. Antologia. Livro 1. Minas Gerais: Editora da Universidade Federal de Uberlândia, 2017.

FARIÑS LEÓN G. Psicología, educación y sociedad. Ciudad de la Habana, Cuba: Editorial Félix Varela, 2007.

FARIÑAS LEÓN, G.; CARNIELO CALEJON, L. Vivência, situação social do desenvolvimento e práxis. In: BERNARDES M. E. M.; ARIAS BEATÓN, G. (org.). Trabalho, educação e lazer. Contribuições do enfoque histórico-cultural para o desenvolvimento humano. São Paulo: Escola de Artes, Ciências e Humanidades, USP, 2017. p. १२3-142.

FREIRE, P. La educación como práctica de la libertad. España: Siglo XXI, 1971. 
FONTES, A. C. de M.; BERNARDES, M. E. M. 0 teatro como expressão intrínseca ao gênero humano. In: ENCONTRO DO PROGRAMA DE PÓS-GRADUAÇÃo EM EDUCAÇÃ0, 26., 2020, São Paulo. Anais [...] São Paulo: Faculdade de Educação da Universidade de São Paulo, 2020. p. 1-10.

GADOTTI, M. Educação Integral no Brasil: inovações em processo. São Paulo: Editora e Livraria Instituto Paulo Freire, 2009.

HELLER, A. 0 cotidiano e a história. 8. ed. São Paulo: Paz e Terra, 2008.

JÄGER, W. Paideia. México: Fondo de Cultura Económica, 1995.

MANACORDA, M. A. História da educação: da antiguidade aos nossos dias. São Paulo: Cortez, 2010.

MANACORDA, M. A. Pedagogía de Vygotsky. Cuadernos Pedagógicos, n. 64, p. 46-57, abr. 1980.

MARTí, J. La edad de oro. La Habana, Cuba: Editorial Pueblo y Educación, 1997.

MARTÍ, J. Obras completas. La Habana: Editorial de Ciencias Sociales, 1975. (Discurso en Hardman Hall, New York, 17 de febrero de 1892, t.4, p. 303) y Cuadernos de apuntes, 1878-1880, 1975 t. 21, p. 134.

MARX, C.; ENGELS, F. Obras escogidas. Moscú: Editorial Progreso, 1986.

MIYARES, J.; FRANCO, R. Reinauguran en la ONU murales "Guerra y Paz" del pintor brasileño Portinari. Noticias ONU, 8 set. 2015. Disponivel em: https://news.un.org/es/audio/2015/09/1410411\#: :text=Despu\%C3\%A9s\%20de\%20casi\%20cinco\%20a\%C3\%Blos,la\%20noche\%20de\%20este\%20martes.\&text=Los\%20 paneles\%20de\%20\%22Guerra\%20y,p\%C3\%BAblico\%20en\%20Brasil\%20y\%20Francia. Acceso en: 18 feb. 2021.

MONTESSORI, M. El método de la pedagogía científica: aplicado a la educación de la infancia. Madrid: Biblioteca Nueva, 2003.

ROUSSEAU, J. J. Obras escogidas. La Habana, Cuba: Editorial Ciencias Sociales, 1973.

SHUARE, M. 0. Las relaciones entre la fisiología y la psicología: la contribución del Enfoque Histórico Cultural. São Paulo: Edições EACH USP, 2021.

SPITZ, R. A. Hospitalism solicitud de la génesis de condiciones psiquiátricas en temprana Niñez. El estudio psicoanalítico de niño, v. 1, p. 53-74, 1945.

SPITZ, R. A. Hospitalism: un informe de continuación sobre investigación descrita en. El estudio psicoanalítico de Niño, v. 2, p. 113-117, 1946.

STEVENSON, W. H.; STIGLER, J. W. The learning gap: why our schools are failing and what we can learn from japanese and chinese education. Nueva York: Touchstone, Simon and Schuster, 1992. 
UBALS ÁLVAREZ, J. M. Educación estética y educación artística: un diálogo recombinante. EduSol, v. 9, n. 26, enero/marzo, p. 91-109, 2009.

UNESCO. Educación de calidad para todos: un asunto de derechos humanos. 2. ed. Santiago: Escritório Regional de Educação para América Latina e Caribe, 2008.

VÁZQUEZ, A. S. Filosofia da práxis. 1. ed. Buenos Aires: Consejo Latinoamericano de ciencias sociales, 2007.

VIGOTSKY, L. S. Historia del desarrollo de las funciones psíquicas superiores. Ciudad de La Habana, Cuba: Editorial Científico Técnica, 1987.

VIGOTSKY, L. S. Imaginación y creación en la edad infantil. Ciudad de la Habana, Cuba: Editorial Pueblo y Educación, 1987.

VIGOTSKY, L. S. Interacción entre enseñanza y desarrollo. In: COLECTIVO DE AUTORES. Selección de Lecturas de Psicología de las Edades I. La Havana: Facultad de Psicología Universidad de La Habana, Editorial del Ministerio de Educación Superior, 1988.

VYGOTSKY, L. S.; LURIA, A. R. El instrumento y el signo en el desarrollo del niño. España: Editor Fundación Infancia y Aprendizaje, 2007.

VIGOTSKY, L. S. Obras Escogidas. Madrid, España: Visor, 1991. Tomo I. Editorial Aprendizaje.

VIGOTSKY, L. S. Obras Escogidas. Madrid, España: Visor. 1995. Tomo III. Editorial Aprendizaje.

VIGOTSKY, L. S. Obras Escogidas. Madrid España: Visor, 1996. Tomo IV. Editorial Aprendizaje.

VIGOTSKY, L. S. Psicología del arte. Barcelona, España: Editorial Barral, 1972.

VIGOTSKY, L. S. Psicología pedagógica: un curso breve. Buenos Aires, Argentina: Aique Editor, 2001.

VIGOTSKY, L. S. Teoría de las emociones: estudio histórico-psicológico. Madrid, España: Ediciones Akal, 2004.

Endereço para correspondência: Rua Salvador Simões 1213, Apto 42 da torre B, 04276-000, São Paulo, São Paulo, Brasil; gariasbeaton@gmail.com 